\title{
Is the IACUC interfering with study design?
}

Slowly and methodically working his way through the Animal Welfare Act (AWA), Dr. Harry Rosen almost jumped out of his chair with excitement when he found what he was looking for. There it was, clearly stating that "Nothing in this Act. . . shall be construed as authorizing the Secretary to promulgate rules, regulations, or orders with regard to design, outlines, guidelines or performance of actual research or experimentation by a research facility as determined by such research facility." Then, as if by magic, when he turned his attention to the regulations of the Act, the first thing he found was the wording he was seeking. The regulations stated that the IACUC could not set standards for the design, performance, or conduct of actual research by the research facility. Half giggling and half delirious, he ran down the hall to Dr. Sam Gooding's lab. With a grand flourish, he barged through the door and exclaimed, "Sam. You and your meddling Committee are illegal. You can't stop my research. It says right here that the IACUC can't interfere with the design of my experiments." Looking up from his desk, Gooding turned and said, "Slow down, Harry. Let me see what you're talking about." Pulling out his copies of the Act and the regulations, Rosen's quivering finger showed Gooding the sections he underlined. "Read it for yourself," he said. "You can't tell me how to design my research." Carefully, Gooding read what Rosen had brought, looked at his friend, and said, "Harry, you're way off base. You've misinterpreted everything. All the IACUC wants to do is make sure that you are going to use the smallest number of animals that can give you scientifically acceptable results."

The story was simple. As part of his research, Rosen wanted to perform anastomoses of the large intestine of rabbits.
In one group of animals he would periodically examine the anastomoses endoscopically, whereas he would euthanize rabbits from another group at specific time points and examine the anastomosis microscopically. Upon review of the study, the IACUC wanted to know what additional knowledge Rosen would gain by having both groups of rabbits, rather than one or the other. Rosen took this question as an affront to his ability to design a study, and he felt that the IACUC should not be interfering with the study design itself. For its part, the IACUC did not see this concern as interfering with the study design; rather, it believed that it was asking a very basic question about animal numbers, and with Rosen refusing to respond to its query, it had no choice but to withhold approval until the issue was resolved.

Was Rosen right, or was the IACUC just doing what it was supposed to do?

\section{RESPONSE}

\section{Understanding is the key}

\section{Mary Ellen Goldberg, BS, VMT}

There are so many issues to consider in this situation that I hardly know where to begin. Let me say that I have encountered this controversial issue more times than I care to admit.

Although there is no indication as to Rosen's age, I would be willing to bet that he's an established investigator who has been doing research for many years. Writing a grant to be funded by an outside funding agency (e.g., National Institutes of Health or National Science Foundation) is very much like laying your soul on the line for the review committee to either chop into pieces or bless you with a funded project. This process occurs every few years for each grant proposed, leaving the investigator drained at the end of each process. I have known quite a few established investigators who find that all the new rules and regulations simply contribute to their suspicion of someone attempting to impede their proposal. Protocol writing and the IACUC review process seem to be just additional obstacles that researchers must surmount to be able to do their work. Members of the IACUC must also take into consideration that a good deal of ego is involved here. So Rosen has received the Committee's letter saying that he has not provided sufficient evidence for them to approve the protocol. The letter presents the facts unequivocally. I can imagine the scene in Rosen's office when he reads the letter from the IACUC. According to the scenario, he refuses to address the issue. This suggests to me that Rosen is too burned out on dealing with reviews and committees to criticize his work. I think he hasn't considered the rationale of the IACUC's thinking. So, he's bent on a quest, instead of discussing with a Committee member what he needs to provide. Can you imagine how many hours he might have spent poring over the AWA? I promise you that such a task is in itself not easy. (It's kind of like reading a tax form without the instructions.) However, he is proceeding up a blind alley because of his perception that the IACUC is merely setting up another blockade. Believing that he is nearing his triumph, he goes to the IACUC Chair and flaunts his findings. Is he thinking logically? No, he "can't see the forest for the trees," so to speak.

Now we come to the Committee Chair's response. The way Gooding addresses "Harry" leads me to conclude that they are friends. Gooding encourages Rosen to focus on the fundamental issue, which concerns the number of animals, not an attempt to block Rosen's work. I'm not sure that many investigators understand the full importance of animal numbers, nor will they ever without some help, patience, and understanding from the IACUC members. As I see it, the issue to be addressed is the necessity of two experimental groups. Rosen 